\title{
Giant dumbbell foramen magnum neurinomas presenting as posterior neck masses: Single-stage removal by posterior midline approach
}

\author{
Sunil K. Gupta, Anand Kumar, Virender K. Khosla \\ Department of Neurosurgery, Postgraduate Institute of Medical Education and Research, Chandigarh - 160 012, India
}

Two patients with giant dumbbell foramen magnum neurinomas are reported. The intradural component was located anterior to the cervicomedullary junction while the extradural and extraspinal portion of the tumor had grown large enough to present as a neck swelling. In both patients total surgical removal was achieved by a single-stage posterior midline approach. Both patients had complete neurological recovery.

Key words: Dumbbell spinal tumors, foramen magnum neurinomas, surgical approach

\section{Introduction}

Dumbbell tumors of the foramen magnum (FM) are uncommon. It is rare for these tumors to extend into the extraspinal and paraspinal region and form a mass in the neck. We report here two patients with giant dumbbell foramen magnum neurinomas. In both patients total surgical removal was achieved in a single stage by a posterior midline approach.

\section{Case Reports}

\section{Case 1}

An 18-year-old male presented with history of left-sided neck swelling since childhood and a progressively increasing weakness of left upper limb for the last four years. He had horizontal gaze-evoked nystagmus on looking to the left and the gag reflex was diminished on the left side. Power in the left upper limb was Grade 4/5. All the deep tendon reflexes were exaggerated and both the plantar reflexes were extensor. There was a diffuse firm nonfluctuant nontender swelling on the left posterior side of the neck, about $6 \times 6 \mathrm{~cm}$ in size.
Magnetic resonance imaging (MRI) demonstrated a giant dumbbell tumor. The intraspinal component was occupying the foramen magnum with gross posterior displacement of the cervicomedullary junction. The extraspinal component formed a large neck mass. The vertebral artery was displaced [Figure 1]. The patient was operated by a standard posterior midline approach and total removal was achieved [Figure 2]. The surgical technique is described below. The patient showed neurological recovery in the immediate postoperative period and in the last two years has remained asymptomatic with no neurological deficit.

\section{Case 2}

A 21-year-old man was admitted with a progressively increasing right-sided neck mass for the last three years, weakness and stiffness of all four limbs for four months, urgency and frequency of micturition along with
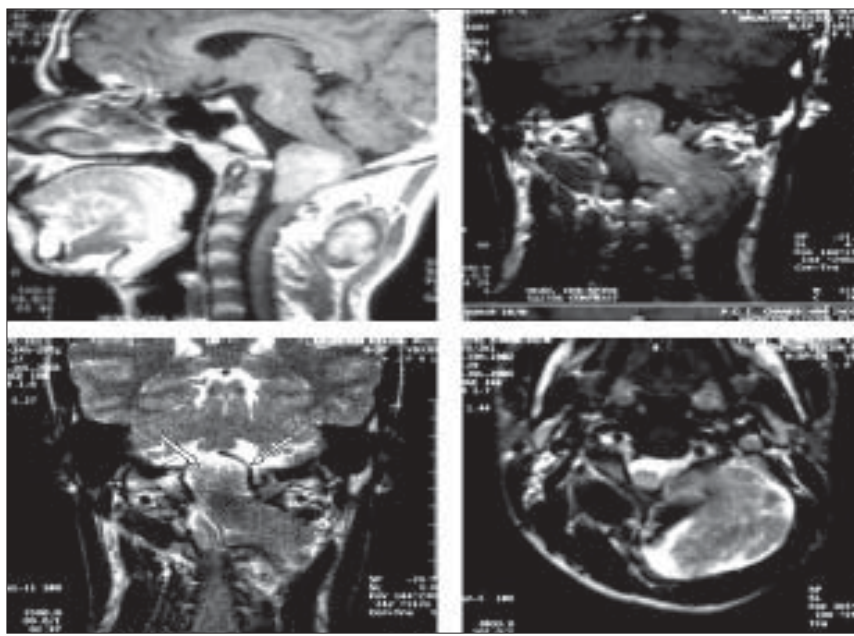

Figure 1: Preoperative MRI scans (Case 1) sagittal, (T1 contrast) coronal (T1 and T2 weighted) and axial (T2 weighted) images depicting the intraspinal and extraspinal extent of the giant dumbbell tumor. The vertebral arteries (arrows) have been displaced by the tumor 


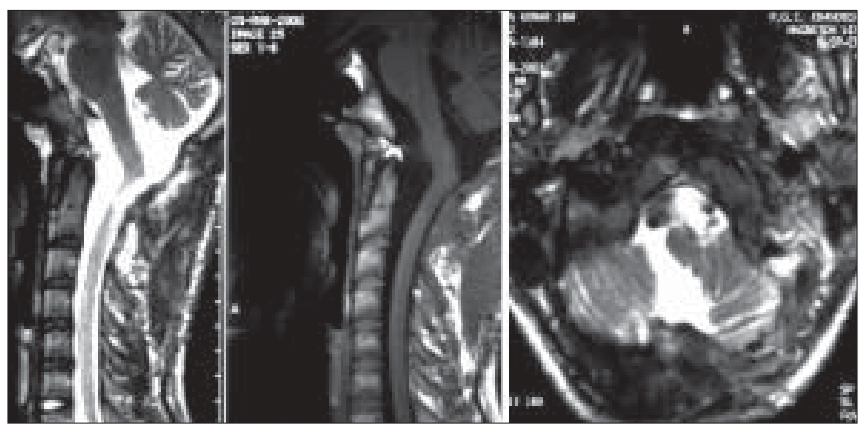

Figure 2: Postoperative MRI images (sagital T1 and T2 weighted, axial T2 weighted) showing complete excision

constipation for last two months He had spastic quadriparesis (Grade 3/5), the pain and temperature sensations were diminished below $\mathrm{C}_{5}$. Both the plantar reflexes were extensor. There was a large nontender neck mass on the right side under the sternomastoid muscle in the posterior triangle of the neck. The MRI demonstrated a giant dumbbell tumor located ventral to the cervicomedullary region with a massive extraspinal extension into the neck. The vertebral artery was displaced by the tumor mass [Figure 3]. A single-stage complete removal [Figure 4] was achieved by the posterior midline approach discussed below. The patient made complete neurological recovery.

\section{Surgical technique}

The patient was placed prone and a midline vertical incision given from the region of the external occipital protuberance to the $\mathrm{C}_{7}$ spinous process. A suboccipital craniectomy with removal of the foramen magnum rim was performed on the side of the tumor. In addition a $\mathrm{C}_{1}$ - $\mathrm{C}_{2}$ hemilaminectomy was done on the same side. In both patients the $\mathrm{C}_{1}$ arch was thinned out by the tumor. $\mathrm{A}$

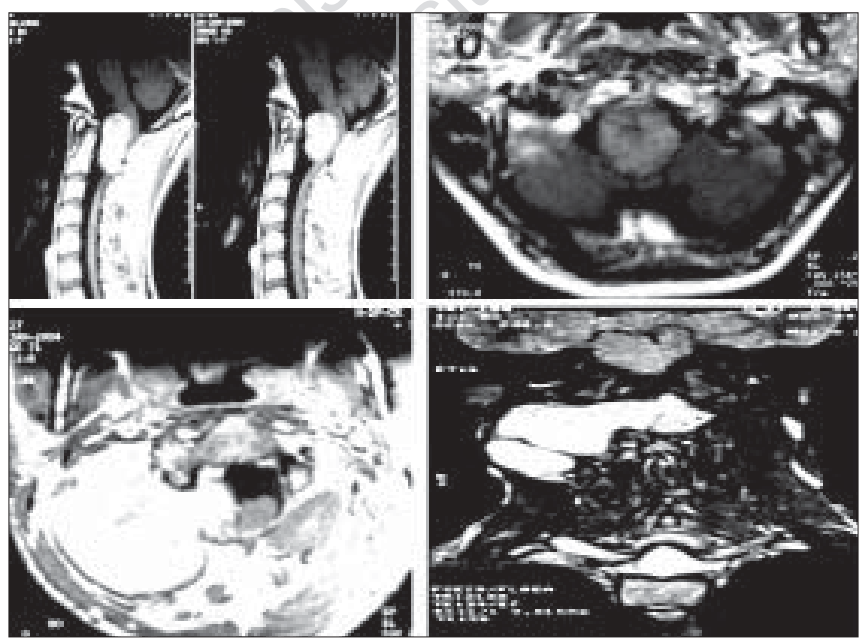

Figure 3: Preoperative MR images (Case 2): Sagittal (T1 weighted) and axial ( $\mathrm{T} 1$ weighted), coronal (T2 weighted) giant dumbbell tumor with extension into the neck. The cervicomedullary junction is severally compressed and displaced posteriorly

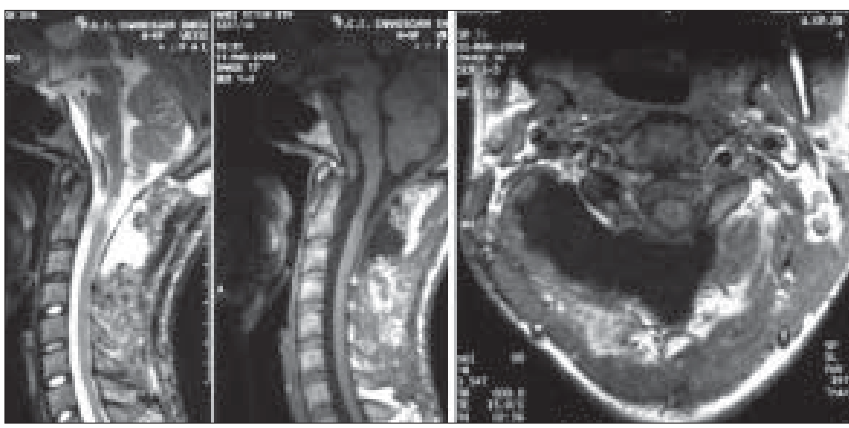

Figure 4: Postoperative MR scan sagittal (T1 and T2 weighted) and axial (T1 weighted) depicting total excision of tumor

limited (less than one-third) $\mathrm{C}_{1}-\mathrm{C}_{2}$ facet joint removal was done on the side of the tumour. The paraspinal muscles were separated from the laminae of $\mathrm{C}_{3}-\mathrm{C}_{7}$. This helped in retraction of the muscles laterally for exposure of the extraspinal component of the neurinoma.

In the first part of the surgery, attention was focused on the extradural component. Before manipulating this tumor, it was disconnected from the intradural part at the level where it exited the spinal canal. This avoided undue traction on the intradural tumor and thus prevented any manipulation or distortion of the cervicomedullary region during removal of the extradural mass. The tumor was initially debulked and then the capsule was dissected from the muscle plane and removed. In both patients, the vertebral artery had been displaced by the tumor and was not encountered during the surgical procedure. Next the dura was opened vertically from the cerebellum up to the $\mathrm{C}_{2}$ level. The dural incision was posterolateral on the side of extradural tumor extension. After internal decompression of the tumour, the capsule was gently separated from the arachnoid plane and removed totally.

\section{Discussion}

Giant dumbbell FM neurinomas are rare. Dumbbell tumors in this region are mentioned in series describing either FM tumors or those reporting cervical spinal tumors. ${ }^{[1-11]}$ In many series of FM tumors no patient had a dumbbell tumor.

Because of the rarity of this type of tumors, there is hardly any report addressing the surgical approach for these lesions. The approaches described pertain to cervical or $\mathrm{C}_{1}-\mathrm{C}_{2}$ region neurinomas. Most authors state that the dumbbell cervical tumors are best removed by a two-stage operation, a posterior approach for removal of the intradural component and an anterior /anterolateral approach for removal of the cervical portion of the tumor. ${ }^{[4,5,8,10]}$ Lot and George ${ }^{[10]}$ described the lateral approach for management of such tumors. Hakuba et a ${ }^{[7]}$ developed a transuncodiscal approach for cervical spinal dumbbell tumors at or below $\mathrm{C}_{2}$ level. The anterior/ 
anterolateral approaches, however, carry the risk of injury to the vertebral artery or its radiculomedullary branches, as well as injury to phrenic, accessory, vagus and hypoglossal nerves. ${ }^{[7]}$

The posterior or posterolateral approaches have been utilized by a few authors for cervical dumbbell tumors. ${ }^{[8,9,11]}$ Mazumdar et $a{ }^{[12]}$ removed a massive neurinoma presenting as a suboccipital mass by the posterior approach. McCormick ${ }^{[11]}$ combined a laminectomy with unilateral facetectomy for single-stage removal of such a tumor. We found the posterior midline approach sufficient for a single-stage complete removal of the giant dumbbell FM tumors with mainly posterior extension. However, if the dumbbell extension is mainly in the anterior neck triangle, it may require a different approach. The $\mathrm{C}_{1}-\mathrm{C}_{2}$ interspace is quite wide and there is no intervertebral foramen between $\mathrm{C}_{1}$ and $\mathrm{C}_{2}$. We feel that it is safer to remove the extradural portion first after disconnecting it from the intraspinal part. This avoids any traction over the intradural component during removal of the extradural tumor. When the extradural component is removed, there is additional wide space available to change the surgical trajectory to a more lateral angle, thus improving access to the anteriorly located intradural tumor. Kyoshima et $a I^{[9]}$ has also emphasized the advantages of the removal of the extradural portion of cervical neurinoma before the intradural component.

Unilateral partial facetectomy is unlikely to lead to any problem of cervical instability. This has been the experience of other authors as well. ${ }^{[7]}$ In both our patients, no more than $1 / 3$ of unilateral facetectomy was performed. Thus spinal fusion was not required.

\section{References}

1. Meyer FB, Ebersold MJ, Reese DF. Benign tumours of the foramen magnum. J Neurosurg 1984;61:136-42.

2. Roberti F, Sekhar LN, Kalavakonda C, Wright DC. Posterior fossa meningiomas: Surgical experience in 161 cases. Surg Neurol $2001 ; 56: 8-21$

3. Sarat Chandra P, Jaiswal AK, Mehta VS. Foramen magnum tumours. A series of 30 cases. Neurol India 2003;51:193-6.

4. Asahi M, Hanakita J, Suwa H, Fukuda M, Namura S, Mizuno M et al. Dumbbell cervical neurinomas with subcutaneous extension: Report of two cases. No Shinkei Geka 1993;21:257-62.

5. Asazuma T, Toyama Y, Maruiwa H, Fujimura Y, Hirabayashi K. Surgical strategy for cervical dumbbell tumours based on a threedimensional classification. Spine 2004;29:E10-4.

6. George B, Lot G, Boissonnet H. Meningioma of the foramen magnum: A series of 40 cases. Surg Neurol 1997;47:371-9.

7. Hakuba A, Komiyama M, Tsujimoto T, Soo Ahn M, Nishimura S, Ohtai T, et al. Transuncodiseal approach to dumbbell tumours of the cervical spinal canal. J. Neurosurgery 1984;61:1100-6.

8. Jho HD. Posterolateral approach for anteriorly located cervical spine tumors: Technical note. Minim Invasive Neurosurg $1998 ; 41: 204-8$

9. Kyoshima K, Uehara T, Koyama J, Idomari K, Yomo S. Dumbbell C, sehwannomas involving both sensory and motor rootlets: Report of two cases. Neurosurgery 2003;53:436-40.

10. Lot G, George B. Cervical neuromas with extradural components: Surgical management in a series of 57 patients. Neurosurgery 1997;41:813-22.

11. McCormick PC. Surgical management of dumbbell tumours of the cervical spine. Neurosurgery 1996;38:294-300.

12. Muzumdar D, Desai K, Goel A, Shenoy A. Unusual massive neurinoma in the suboccipital region: Case report. Neurol Med Chir (Tokyo) 2000;40:280-2.

Accepted on 12-08-2006

Source of Support: Nil, Conflict of Interest: None declared. 